https://doi.org/10.7203/Normas.3.4671

\title{
ORTOTIPOGRAFÍA CIENTÍFICA EN PUBLICACIONES MÉDICO- QUIRÚRGICAS: LA NORMATIVA ACADÉMICA RELATIVA A LA PREFIJACIÓN
}

\author{
SCIENTIFIC TYPOGRAPHICAL SYNTAX OF MEDICAL AND SURGICAL JOURNALS: \\ THE SPANISH ACADEMIC RULES ON PREFIXING
}

Manuel José AgUILAR RuIZ

Tecnolingüística S. L.

\section{RESUMEN:}

El objetivo del presente artículo es analizar el grado de cumplimiento de la normativa académica relativa a la correcta escritura de las palabras prefijadas (recogida en la nueva Ortografía de 2010) que realizan algunas publicaciones periódicas de carácter científico-técnico $\mathrm{y}$, en concreto, del ámbito médico-quirúrgico. Se trata de una labor de profundización en un estudio anterior (Aguilar Ruiz 2012: 9-12). Para ello, comentamos los errores e incorrecciones más recurrentes de un corpus de publicaciones científicas argentinas de finales de 2012.

PALABRAS CLAVE: Ortografía (2010), ortotipografía, nuevas normas académicas, prefijación, revistas de medicina y cirugía argentinas

\section{ABSTRACT:}

The aim of this paper is to analyze the degree of compliance on the correct academic writing prefixed words (contained in the new spelling) that perform some scientific journals and technical (and, specifically, the medical field and surgical). This is a work of depth in a previous study (Aguilar Ruiz 2012: 9-12). To do this, we discuss the most frequent errors and misconduct of a corpus of scientific publications Argentine late 2012.

KEY WORDS: Orthography (2010), typographical syntax, new Royal Spanish Academy rules, prefixing, Argentine medical and surgical journals 


\section{INTRODUCCIÓN}

La aparición de la nueva Ortografía académica, publicada en 2010 por la Real Academia Española (RAE) y la Asociación de Academias de la Lengua Española (ASALE), ha supuesto un serio intento de normativización de la ortografía de la lengua española de ambos lados del Atlántico, hecho que ya se venía planteando en obras académicas anteriores como el Diccionario panhispánico de dudas (2005) y, extraacadémicamente, en diversos manuales. En el presente trabajo pretendemos analizar el seguimiento que, dos años después de la aparición de la Ortografía ${ }^{1}$, llevan a cabo algunas publicaciones periódicas de carácter científico (y, en concreto, del ámbito médico-quirúrgico) en cuanto a las normas relativas a la prefijación, ya que, como analiza Martín Camacho (2004: 58 y ss.), la creación léxica mediante la adición de prefijos es uno de los procedimientos más rentables de la creación de términos en el lenguaje científico ${ }^{2}$. Para ello hemos realizado consultas en un extenso corpus de revistas de medicina y cirugía publicadas a finales del año 2012, limitándonos al ámbito geográfico concreto de las publicaciones especializadas argentinas. Concebimos el presente trabajo como una labor de profundización en una investigación anterior sobre hábitos ortotipográficos en el español panhispánico (Aguilar Ruiz, 2012: 9-12), aunque aquí, por razones de espacio, reducimos el ámbito geográfico a un país hispanohablante concreto.

En el epígrafe 2 de la presente investigación comentamos de manera detallada la normativa general académica relativa a la prefijación, orientada a los textos especializados del ámbito médico-quirúrgico, para observar detenidamente a continuación las excepciones a la norma general (epígrafe 3) y obtener unas conclusiones que constituyen una recapitulación del trabajo (epígrafe 4).

Seguimos, básicamente, la metodología adoptada en el estudio antes citado. Hemos seleccionado, pues, una publicación divulgativa (la revista Médicos) y, sobre todo revistas especializadas, publicadas on-line, con un relativamente alto índice de impacto y pertenecientes a distintas especialidades médicas (cardiología, hematología, urología, endocrinología, pediatría, etc.), biomédicas (microbiología) y quirúrgicas (de cirugía general) ${ }^{3}$. A lo largo del artículo, los ejemplos se citan siempre mediante una clave identificativa (la sigla del título de cada trabajo en cuestión, tomando algunas de las palabras clave de cada uno de ellos); al final de este, tras la bibliografía, se facilita una relación (que hemos llamado «Publicaciones científicas citadas») que ordena

\footnotetext{
${ }^{1}$ Ortografía de la lengua española; en adelante, OLE.

${ }^{2}$ Vid. De la Riva Fort (2011: 131).

${ }^{3}$ El corpus está integrado por las siguientes publicaciones periódicas argentinas, la mayoría obtenidas a través de la editorial Elsevier y los índices bibliográficos de Scielo y Medigraphic: Archivos argentinos de pediatría, Hematología, Insuficiencia cardíaca, Médicos, Revista americana de medicina respiratoria, Revista argentina de cardiología, Revista argentina de cirugía, Revista argentina de dermatología, Revista argentina de endocrinología y metabolismo, Revista argentina de microbiología, Revista argentina de radiología, Revista argentina de urología, Revista de la Asociación Argentina de Ortopedia y Traumatología, Revista hispanoamericana de hernia y Salud colectiva. No obstante, ante el ingente número de documentaciones válidas, nos hemos visto obligados, por motivos de espacio, a realizar una selección que ha dejado fuera de los ejemplos aquí aportados a algunas de las publicaciones consultadas que forman nuestro corpus.
}

NORMAS. REVISTA DE ESTUdIOS LINGÜÍSTICOS HISPÁNICOS, NÚMERO 3 (AÑO 2013):

http://www.uv.es/normas

(ISSN 2174-7245) 
alfabéticamente las distintas claves, con lo que se puede obtener así su referencia bibliográfica completa.

Dejamos a un lado los procedimientos de sufijación y de composición (ampliamente documentados en el corpus y que originan problemas específicos) para centrarnos exclusivamente, como ya hemos comentado, en las principales dificultades relacionadas con la correcta escritura de las palabras prefijadas.

\section{LA NORMATIVA ACADÉMICA RELATIVA A LA CORRECTA ESCRITURA DE LAS PALABRAS PREFIJADAS}

Se conoce como prefijación el proceso de formación de palabras consistente en anteponer un morfema o afijo (denominado prefijo) a una base léxica, que puede ser una palabra ya formada o un tema de origen grecolatino (NGLE, § 10.1.1a). Ya hemos analizado en otras ocasiones (Aguilar Ruiz, 2012: 9 y 2013a: 102) que la normativa académica establece como norma general que un prefijo ha de escribirse siempre unido a la palabra a la que prefija, nunca separado de ella (ni por un espacio en blanco ni por un guion), sino «soldado gráficamente a la base a la que afecta» (OLE, cap. III, $\S$ 4.1.1.2.6).

2.1. Como se establece en la nueva Ortografía (cap. III, § 4.1.1.2.6 y cap. V, § 2.2.2), las voces prefijadas constituyen una unidad morfológica y prosódica (al ser los prefijos elementos átonos, carentes de acento prosódico), por lo que los prefijos que las formen se han de escribir siempre unidos gráficamente a la base léxica a la que se refieran (cuando esta sea una sola palabra) ${ }^{4}$. Sin embargo, por errores debidos al desconocimiento de la norma o -en otros casos- por influencia del peso que la lengua inglesa tiene en las publicaciones científicas de carácter médico-quirúrgico (vid. Claros 2008: 145 y ss.), se documentan múltiples concurrencias de escritura separada, bien mediante un espacio en blanco o bien mediante guion. Así, si tomamos el prefijo de origen griego anti-, con el significado opositivo de 'opuesto o contrario a' en los términos anticoagulación, antitimocito y anticentrómero (documentados en los dos ejemplos siguientes), la escritura correcta, refrendada por la normativa académica, sería el ejemplo (1), y son incorrectas las escrituras documentada en los ejemplos (2) y (3) (que ofrecen las dos posibilidades erróneas de escritura):

(1) [...] el deseo de embarazo de las mujeres en edad fértil y su limitación con la anticoagulación (CR: 351).

(2) Se administró globulina *anti timocito (ATG) a todos los pac. [pacientes] (TCPHD: 69).

(3) [...] registrándose solo como datos positivos un Atc [anticuerpo] *anti-centrómero (títulos bajos) y una VSG de $118 \mathrm{~mm}$ (MMRECE: 155). trabajo.

${ }^{4} C f r$., no obstante, y como ejemplo de determinadas excepciones, el epígrafe 2.1 .5 del presente

${ }^{5}$ Los significados de los prefijos que ofrecemos a partir de aquí a lo largo todo el trabajo están tomados del DRAE, OLE o NGLE, aunque por razones de espacio y de fluidez textual no especificados la fuente en cada caso concreto.

NORMAS. REVISTA DE ESTUdIOS LINGÜÍSTICOS HISPÁNICOS, NÚMERO 3 (AÑO 2013):

http://www.uv.es/normas

(ISSN 2174-7245) 
2.1.1. De entre este tipo de afijos antepuestos a una raíz, parecen muy recurrentes algunos prefijos de significado locativo del tipo ante-, circun-, entre-, exo-, extra-, hipo-, infra-, intra-, pos(t)-, pre-, sobre-, sub-, supra- tra(n)s-, etc. ${ }^{6}$, presentes normalmente en adjetivos relacionales denominales, que indican «la posición o la situación de algo considerada en relación con lo que el nombre designe» (NGLE, § 10.4) (en nuestro caso, la región anatómica del enunciado). Todas las documentaciones presentan una escritura correcta excepto la número (12):

(4) $[\ldots]$ además pueden existir masas adenopáticas supraesternales, adenopatías hiliares pulmonares y supraclaviculares (TLPM: 166).

(5) Además, en pacientes sin derivación suprapúbica, la hidrodistención generada por la micción no permite determinar en forma adecuada la uretra proximal (AAIMY: 162).

(6) Al momento del muestreo, se registró el estado clínico de cada animal (diarrea, bajo peso, edema submandibular) (OEDPP: 157).

(7) padecían detrusor neurogénico suprasacral (ERCA: 223).

(8) Con finalidad diagnóstica, Daniels, en 1947, describió la biopsia de la grasa preescalénica mediante una incisión supraclavicular (ATCT: 44).

(9) Además, en el cáncer de pulmón izquierdo, debe añadirse la exploración de las estaciones subaórticas y paraaórtica (ATCT: 45).

(10) La pieza quirúrgica se extrae en bolsa por extensión de $3 \mathrm{~cm}$ de la incisión supraumbilical (DTL: 65).

(11) Una correcta evaluación preoperatoria del muñón rectal permite establecer su longitud respecto de la ubicación intraperitoneal (VLRTI: 34).

(12) Se identificaron actinomices en muestras cervicovaginales de mujeres que utilizaban Dispositivo *Intra Uterino (DIU) (AP: 74). ${ }^{7}$

2.1.2. En este tipo de textos especializados es también muy recurrente el procedimiento de prefijación para aportar un significado temporal a la voz (normalmente sustantivo) (vid. NGLE, § 10.5), que especifica, por ejemplo, el tiempo quirúrgico, indicando anterioridad (como pre- o ante-), simultaneidad (como intra-) o posterioridad (como $\operatorname{pos}[t]-):^{8}$

${ }^{6}$ Con los significados espaciales de ante- ('anterioridad en el espacio'), circun- ('alrededor'), entre- ('en medio o en posición intermedia'), exo- ('fuera'), extra- ('fuera de'), hipo- ('debajo de'), infra('debajo de' o 'por debajo de'), intra- ('dentro o en el interior'), pos(t)- ('posterioridad en el espacio'), pre- ('anterioridad en el espacio'), sobre- ('encima de' o 'por encima de'), sub- ('debajo de' o 'por debajo de'), supra- ('encima de' o 'por encima de'), tra(n)s- ('detrás de', 'al otro lado de' o 'a través de').

${ }^{7}$ Nótese que en este caso la incorrección de escribir el prefijo (intra) separado de su base léxica (uterino) puede haberse debido a la formación de la sigla $D I U$, que ha sido creada tomando dicho prefijo como lexía independiente e integrante del término complejo. Este hecho, por cierto, resulta muy habitual en la formación de siglas en el ámbito científico-técnico, como reconoce la propia Academia (OLE, cap. $\mathrm{V}, \S 3.3 .1$ ), que ofrece como ejemplos DDT (diclorodifeniltricloroetano), ADN (ácido desoxirribonucleico), UV (ultravioleta) y EPO (eritropoyetina). También resulta incorrecto, por otra parte, la mayusculización de la letra inicial de cada uno de los integrantes léxicos desarrollados que conforman la sigla.

${ }^{8}$ Con los significados de: pre- y ante- ('anterioridad en el tiempo'), intra- ('simultaneidad') y $\operatorname{pos}(t)$ - ('posterioridad'). Por otro lado, para profundizar en las innovaciones gráficas del sufijo de significado temporal o locativo pos(t)-, vid. el epígrafe 2.3.

NORMAS. REVISTA DE ESTUDIOS LINGÜÍSTICOS HISPÁNICOS, NÚMERO 3 (AÑO 2013):

http://www.uv.es/normas

(ISSN 2174-7245) 
(13) Figura 2. Localización preoperatoria de ganglio centinela mediante linfogammagrafía y SPECT-CT (MPUM: 263).

(14) No se observaron infecciones de prótesis, ni otras complicaciones perioperatorias (ERCA: 223).

(15) El número de conversiones, mortalidad y complicaciones, se halla en relación directa con la experiencia del equipo quirúrgico y los accidentes intraoperatorios (VLRTI: 33).

(16) La mortalidad durante el procedimiento, intrahospitalaria y a los 30 días, fue del $5 \%$ (BCIDPA: 362).

Serían erróneas, pues, las siguientes documentaciones, bien por la escritura del prefijo separada de su base léxica ${ }^{9}$ (ejemplos 17-19), bien por su escritura con guion (20 y 21):

(17) Las muestras fueron obtenidas por punción venosa *post ayuno nocturno (VPTH: 64).

(18) [otros estudios] han confirmado que la capacidad de llenado diastólico y la reducción de la fracción de eyección sistólica *post ejercicio se registraron en el $73 \%$ de los pacientes (PCA: 127).

(19) La duración del monitoreo semanal se mantuvo hasta el día +100 o hasta el +365 *post trasplante si el paciente había presentado reactivación (TCPHD: 72).

(20) La normalización de la coagulación *pre-procedimiento puede verse seguida de un retorno al riesgo basal de tromboembolismo (RITAPPI: 186).

(21) Hasta el momento se conoce que la inoculación *pre-servicio con taquizoítos vivos protege contra la infección y el aborto (ADVNB: 227).

2.1.3. Son bastante frecuentes, además, prefijos opositivos y de actitud favorable, como anti- y contra- ('opuesto o contrario a') ${ }^{10}$ y pro- ('a o en favor de'):

(22) Se administró globulina *anti timocito (ATG) a todos los pac. [pacientes] (TCPHD: 69).

(23) [...] registrándose solo como datos positivos un Atc [anticuerpo] *anti-centrómero (títulos bajos) y una VSG de $118 \mathrm{~mm}$ (MMRECE: 155).

(24) El paciente presentó una muy buena respuesta parcial (criterios de respuesta del IMWG 2006) al tratamiento *anti-mieloma con 3 drogas y excelente recuperación dermatológica, continuando en plan de intensificación con *auto-trasplante de médula ósea (MMRECE: 160).

(25) Se utilizó como anticuerpo secundario un monoclonal anti- $\operatorname{IgG}$ anti-ratón o anti-IgG anti-conejo (OEDPP: 157).

Así pues, la escritura correcta con este tipo de prefijos aparece en las documentaciones siguientes:

(26) La detección del SNP-308 G/A del TNF $\alpha$ podría ser útil para futuros ensayos clínicos, particularmente aquellos que bloqueen o modulen la actividad de esta citoquina proinflamatoria (PATNFA: 152).

\footnotetext{
${ }^{9}$ Aparte de, como se verá en el epígrafe 2.3 anunciado en la nota anterior, la conservación de la consonante $-t$ final del prefijo pos $(t)$-.

${ }^{10}$ Para el adverbio de negación no con un uso similar al de un prefijo privativo, vid. el epígrafe 3.2.
}

NORMAS. REVISTA DE ESTUdIOS LINGÜÍSTICOS HISPÁNICOS, NÚMERO 3 (AÑO 2013):

http://www.uv.es/normas

(ISSN 2174-7245) 
(27) [...] el deseo de embarazo de las mujeres en edad fértil y su limitación con la anticoagulación (CR: 351).

2.1.4. En este tipo de textos especializados podemos observar la aparición de otros tipos de prefijos, como los que comportan significado aspectual iterativo (como re-, 'acción repetida'), reflexividad (como auto-, 'por uno mismo') o asociación (como co-, 'conjuntamente o con otros'), entre otros. Siguiendo la norma general, pues, resultan erróneas las escrituras siguientes:

(28) El punto critico [sic] al suspender el tratamiento es el de evitar las posibilidades de un [sic] *re-trombosis y, al mismo tiempo prevenir una complicación hemorrágica (RITAPPI: 185).

(29) El paciente presentó una muy buena respuesta parcial (criterios de respuesta del IMWG 2006) al tratamiento *anti-mieloma con 3 drogas y excelente recuperación dermatológica, continuando en plan de intensificación con *auto-trasplante de médula ósea (MMRECE: 160).

(30) [...] funciona también como un *co-activador transcripcional de factores de transcripción generales y de factores de transcripción hematopoyéticos (ELMA: 180).

(31) Inicialmente se plantearon como diagnósticos diferenciales esclerodermia difusa versus manifestación cutánea de síndrome *para-neoplásico (MMRECE: 155).

(32) El genotipo -308 A/A17 y el alelo -308 A18 del TNF $\alpha$ fueron encontrados *sobrerepresentados en pacientes con SMD [síndromes mielodisplásicos] (PATNFA: 148).

(33) Sin embargo, la mayoría [de los pacientes con cáncer diferenciado de tiroides] tiene buena *super-vivencia (CTR: 23).

Mientras que sí podemos considerar correctas las que documentamos a continuación:

(34) Las alternativas a esta circunstancia son la dilatación uretral con balón, la uretrotomía interna, y la reanastomosis (EUAT: 171).

(35) Miller et al. realizaron un ensayo con esta cepa inoculando ratones antes de la preñez y obtuvieron una reducción de la transmisión transplacental ( $A D V N B: 223)$.

(36) Las posibilidades de hallar extrasístoles aumentan cuando el tiempo evolución de la enfermedad es prolongado (PCA: 128).

(37) Son necesarias series con seguimientos más prolongados para que se pueda evaluar el impacto de la necesidad de reoperación del autoinjerto y/o del homoinjerto (CR: 352).

2.1.5. De la misma manera, el prefijo ex-con el significado temporal de 'que fue y ya no es' y antepuesto a cargos u ocupaciones que constituyan una base léxica univerbal (del tipo director, jefe, presidente, etc.), ha de escribirse siguiendo la norma general de voces prefijadas:

(38) [Dr. Ernesto van der Kooy] *Ex Director [sic] del Hospital Municipal del Pilar (EGNCA: $34)^{11}$.

${ }^{11}$ La inicial mayúscula que presenta la voz *Director aquí sería, además, incorrecta, ya que entre las prescripciones que da la normativa académica respecto al uso de la mayúscula inicial está la de evitar esta en sustantivos que designan cargos u ocupaciones de cualquier rango «por su condición de nombres

NORMAS. REVISTA DE ESTUDIOS LINGÜÍSTICOS HISPÁNICOS, NÚMERO 3 (AÑO 2013):

http://www.uv.es/normas

(ISSN 2174-7245) 
Hasta la publicación de la nueva Ortografía en 2010, se prescribía (por ejemplo, en el $D P D$ ) su escritura separada por un espacio de su base léxica, a diferencia del resto de los prefijos. Sin embargo, la nueva normativa académica establece que este prefijo ha de escribirse soldado a su base (esto es, exdirector), al igual que todos los demás prefijos. No obstante, sí se tiene que escribir separado del término al que se refiere cuando este sea una expresión pluriverbal (como podría ser ex primer ministro, ex teniente coronel o ex director general, siguiendo los ejemplos de la Ortografía).

2.1.6. Queremos llamar la atención sobre las dos documentaciones siguientes, (39) y (40), que presentan dos soluciones distintas para lo que debería ser una misma escritura univerbal. Cuando el término en cuestión es el resultado de la unión de un prefijo que termina en vocal con una base que comienza por el fonema vibrante múltiple (representado gráficamente por la grafía $r$ - en posición inicial), la escritura de esta voz prefijada ha de adaptar la grafía de la erre doble ( $r r)$, como la voz monorreno en el caso número (39):

(39) Un paciente era monorreno funcional y presentaba una creatininemia de $1,8 \mathrm{mg} / \mathrm{dl}$, con un tumor de $4 \mathrm{~cm}$ periférico (ETINPL: 187).

Resulta incorrecta, pues, la solución *autoreactivos del número (40), por más que el término se haya escrito como una unidad verbal, ya que con dicha grafía se habría de leer en español, en un principio, con la vibrante simple $[r]$ :

(40) La glándula tiroidea se convierte así en un campo de batalla entre linfocitos *autoreactivos por un lado y tirocitos por el otro (ATMPTH: 142).

\subsection{Las locuciones adjetivas gram positivo y gram negativo (y sus variantes)}

Respecto a los términos para clasificar organismos microscópicos, la Academia, en su avance de la nueva edición del $D R A E^{12}$, prefiere las escrituras gram positivo o gram negativo, esto es, su realización mediante una locución adjetiva de estructura binomial y con el apellido del descubridor de dicha técnica diferencial con minúscula inicial: $^{13}$

(41) Se analizaron 191 episodios de bacteriemias monomicrobianas por bacilos gram negativos correspondientes a 189 pacientes atendidos en el Hospital Naval y en el Hospital Británico de la Ciudad Autónoma de Buenos Aires, durante el año 2010 (EADFH: 165-166).

(42) Capnocytophaga sputigena es un bacilo gram negativo fusiforme que pertenece a la familia Flavobacteriaceae y al género Capnocytophaga (BFACS: 170).

\footnotetext{
comunes, tanto si se trata de usos genéricos $[\ldots]$ como si se trata de menciones referidas a una persona concreta» (OLE, cap. IV, § 4.2.4.1.6).

${ }^{12} \mathrm{Si}$ realizamos la búsqueda de Gram, lo que nos direcciona a http://lema.rae.es/drae/?val=gram [Consulta: 01/09/2013].

${ }^{13}$ Vid. Aguilar Ruiz (2013b).
}

NORMAS. REVISTA DE ESTUDIOS LINGÜÍSTICOS HISPÁNICOS, NÚMERO 3 (AÑO 2013):

http://www.uv.es/normas

(ISSN 2174-7245) 
Se consideran incorrectas, pues, las escrituras que unen ambos componentes mediante un guion (por ejemplo, *Gram-positivo o *gram-negativo), conservan el apellido con mayúscula inicial (*Gram negativa) o presentan el término positivo o negativo reducido a su símbolo matemático respectivo (*Gram + o *Gram -). Se documentan escrituras, incluso, que conmutan la $-m$ final del componente nuclear de la locución por una $-n(*$ gran $)$, aunque en estos casos puede tratarse en gran parte de una errata debida a un tecleo erróneo o a la autocorrección ortográfica del procesador de textos empleado:

(43) La Actinomicosis [sic] es una infección supurativa causada por la bacteria anaerobia *gran [sic] positiva [...] llamada Actinomyces israelii (AP: 74).

\subsection{Innovaciones ortográficas del prefijo culto pos(t)-}

El prefijo de origen latino post-, con significado general locativo ('detrás de') o temporal ('después de') es altamente rentable en español. También lo es en el lenguaje especializado médico-quirúrgico, como demuestra su reiterado empleo en nuestras documentaciones, en las que aparece, fundamentalmente, para concretar las regiones anatómicas o para expresar el tiempo quirúrgico. La nueva normativa académica (OLE, cap. I, $\S 6.5 .2 .2 .2 .3$ ) recomienda la reducción de la $t$ - final de dicho prefijo (con el resultado de pos-) no solo en los casos en los que la base que lo incorpora empiece por consonante (con lo que se evita el encuentro de tres consonantes seguidas), sino también cuando esta comience por vocal ${ }^{14}$.

Así, en el caso de que la preposición post- prefije una palabra que empiece por consonante (como quirúrgico, cirugía, digestión, menopáusico, dilatación o neumonectomía), la normativa académica declara su preferencia a la escritura pos-, como se realiza en las documentaciones siguientes:

(44) En las mujeres posmenopáusicas, los niveles de colesterol total y el colesterol transportado por la lipoproteína de baja densidad (C-LDL) están aumentados comparado con los hallados en las mujeres premenopáusicas (REVG: 54).

(45) fragmento posdigestión con pepsina (FEEAH: 136).

(46) Último ingreso al 8vo [sic] mes posquirúrgico por disnea (ACAS: 78).

(47) En estos casos se observó una expansión asimétrica de la válvula luego del implante, que se corrigió con la posdilatación (BCIDPA: 362).

Por lo tanto, queda claro que la normativa académica aconseja evitar realizaciones como las siguientes (muy recurrentes, como ya hemos comentado, en los textos médicoquirúrgicos):

${ }^{14}$ La nueva Ortografía justifica esta escritura debido a la escasa realización oral que tiene el grupo fónico -st- en posición de cierre silábico (sobre todo cuando se da un encuentro triconsonántico originado por el prefijo post- más una base léxica que empieza en consonante). Si bien la Academia tan solo «recomienda» esta escritura por resultar «preferible» (OLE, cap. I, § 6.5.2.2.2.3), es mediante la reducción de esta $t$ - del prefijo como ya aparecen lematizadas en el DRAE voces tales como posparto (como ejemplo de base léxica que comienza por consonante) o posoperatorio (como base léxica que empieza por vocal).

NORMAS. REVISTA DE ESTUdIOS LINGÜÍSTICOS HISPÁNICOS, NÚMERO 3 (AÑO 2013):

http://www.uv.es/normas

(ISSN 2174-7245) 
(48) Esta comienza el primer día *postquirúrgico y se mantiene usualmente durante siete días (CNILH: 250).

(49) El estudio anatomopatológico reveló reacción granulomatosa *postcirugía con células multinucleadas gigantes (MPUM: 263).

(50) Azorin y col [sic] describieron la técnica que denominaron cirugía mediastínica videoasistida para el cierre de una fístula *postneumonectomía izquierda (ATCT: 51).

En el caso en el que la preposición post- preceda a una base léxica que comience por vocal, la Academia también prescribe la eliminación de la -t- en la escritura, por lo que las soluciones adoptadas en (51-53) serán preferibles siempre a la de (54-57): ${ }^{15}$

(51) En la segunda semana posinoculación, se observó que los animales inoculados con el inmunógeno desarrollaron anticuerpos específicos contra N.caninum (ADVNB: 226-227).

(52) Un paciente presentó una fístula grado $C$ que se manifestó al séptimo día posoperatorio (DTL: 66)

(53) La mayor preocupación de la cirugía de Ross continúa siendo la incertidumbre respecto de la durabilidad de los sustitutos valvulares, principalmente a partir de la segunda década del posoperatorio ( $C R: 352$ ).

(54) Se debió colocar un stent endovascular en arteria gastroduodenal el día 14 *postoperatorio (DTL: 66).

(55) En la fase *postoperatoria inmediata, no hubo fallas atribuibles al factor no humano (ILVCS: 15).

(56) [...] el 19\% de los pacientes presentaron falla renal aguda *postoperatoria dentro de los 30 días (ETINPL: 187).

(57) $[\ldots]$ sin complicaciones intraoperatorias ni *postoperatorias inmediatas salvo la falla de tratamiento en 6 pacientes (ERCA: 223).

Teniendo en cuenta todo lo dicho anteriormente sobre la correcta escritura del prefijo pos $(t)$-, serán siempre incorrectas realizaciones como las que hemos documentado en los ejemplos siguientes, tanto si la base léxica prefijada comienza por consonante $(59,60,61$ y 63) o vocal (58 y 62): unas, por presentar una escritura unificada, bien en forma univerbal (58), bien unida con guion (59-62); otras, por separar mediante un espacio en blanco el prefijo y su base léxica (63):

(58) El primer control *postoperatorio se efectuó a los 4 días, siendo el resto de los controles cada 7 días hasta el momento de extracción de la sonda (AAIMY: 161).

(59) Todos los pacientes padecían incontinencia urinaria severa *post-prostatectomía radical, mojando un promedio de 8 paños/día (EUAT: 168).

(60) Las etiologías en dicha publicación, fueron *post-prostatectomía radical (87 \%), *postadenomectomía $(6,5 \%)$, *post-radioterapia prostática $(3,2 \%)$ y *post-extracción de stent uretral y uretroplastia $(3,2 \%)$ (EUAT: 171).

(61) El foco séptico fue: [sic] absceso dentario en 9 pacientes y absceso submaxilar *posfractura (MND: 8).

(62) Todos los enfermos tratados presentaron alguna complicación *pos-operatoria (MND: 9).

${ }^{15}$ Aun cuando la eliminación de esta - $t$ - en posición intervocálica pueda originar algunas grafías extrañas como posextracción, posadenomectomía o posinoculación (vid. Aguilar Ruiz, 2013: 104) y en las que, en cierto sentido, se puede perder la conciencia etimológica del prefijo $\operatorname{pos}(t)$-.

NORMAS. REVISTA DE ESTUdios LINGÜíSTICOS HISPÁNICOS, NÚMERO 3 (AÑO 2013):

http://www.uv.es/normas

(ISSN 2174-7245) 
(63) [...] siendo internada [la paciente] en una oportunidad por episodio de vómitos y diarrea *pos quimioterapia (ACAS: 78).

\subsection{Vocales geminadas en interior de palabra debido a la unión de un prefijo con su base léxica}

La normativa académica se muestra algo imprecisa, sin embargo, al no tomar partido de forma clara en el caso de voces prefijadas en las que la vocal final del prefijo es la misma que la vocal inicial de la base léxica. En el caso de palabras como metaanfetamina, preeclamsia, antiinflamatorio, endoóseo, monoovular, etc., ¿se ha de mantener en su grafía el encuentro de esas dos vocales idénticas o, por el contrario, se han reducir a una sola en su escritura, con el resultado de metanfetamina, preclamsia, antinflamatorio, endóseo, monovular? La doctrina académica permite, de momento, estos dobletes originados por la anteposición de un prefijo (o un elemento compositivo), prefiriendo la variante gráfica simplificada si la voz en cuestión ha generalizado la simplificación articulatoria a nivel oral o si esta simplificación gráfica no impide o dificulta el reconocimiento y comprensión del vocablo por parte del receptor (OLE, cap. I, § 6.5.1.1.1). El motivo de la preferencia por la forma con vocal reducida, como afirma la misma Ortografía (cap. I, § 6.5.1.1.1), es que en los términos con una alta frecuencia de uso la grafía simplificada suele acabar reemplazando enteramente a la grafía etimológica que conserva la vocal doble. ${ }^{16}$ De manera que admite reiteradamente que escrituras minoritarias como supraórtico, extrabdominal, contranálisis, polinsaturado, dermóptica, ginecobstetricia o quimiorganotrofo (tomando los mismos ejemplos de la Ortografía que forman parte del léxico médico especializado) no han de resultar censurables frente a supraaórtico, extraabdominal, contranálisis, poliinsaturado, dermoóptica, ginecoobstetricia y quimioorganotrofo, sus correspondientes grafías conservadoras. Como ya observamos en otro momento (Aguilar Ruiz, 2013a: $113 \mathrm{y}$ 117-8), la vaguedad y ambigüedad en este caso le ha valido a la Academia numerosas objeciones y críticas por parte de estudiosos como Bezos López (2011) o De la Riva Fort (2011: 133), entre otros. Al igual que estos autores, para la escritura de los términos especializados del lenguaje biomédico recomendamos siempre respetar la grafía etimológica frente a la simplificada (vid. Aguilar Ruiz, 2013a: 113 y 117-8), como la voz metaanálisis en el ejemplo siguiente:

(64) [...] podemos afirmar que son similares a las de las grandes series y metaanálisis realizados (ERCA: 224).

Obviamente, resultarán erróneas siempre las escrituras de las documentaciones (65) y (66), en las que ambos componentes aparecen separados por un guion:

(65) En un *meta-análisis realizado por Corsten y col, [sic] los autores observaron que el debridamiento cervical era con frecuencia insuficiente (ATCT: 50).

${ }^{16}$ Recordemos casos de voces en las que la evolución histórica ha acabado imponiendo la grafía simplificada en muchas de ellas, como paraguas (< paraaguas), resfriar (< reesfriar) o drogadicto (drogaadicto), por ejemplo.

NORMAS. REVISTA DE ESTUdIOS LINGÜÍSTICOS HISPÁNICOS, NÚMERO 3 (AÑO 2013):

http://www.uv.es/normas

(ISSN 2174-7245) 
(66) $\mathrm{Ni}$, mucho menos, su liso reemplazo por la de otros, reflotada de * "meta-análisis" cuyos puntos de salida y de llegada no se conocen sino de mentas (RIPEC: 72 ) ${ }^{17}$

De esta manera, cuando la prefijación a una base léxica ocasione el encuentro de una secuencia -ii- (como cuando entran en acción prefijos o elementos compositivos de origen culto del tipo anti- di-, mini-, multi-, pluri-, poli-, semi-, toxi-, etc.; vid. OLE, cap. I, § 6.5.1.1.4), para la normativa académica resultarían válidos tanto el mantenimiento gráfico de dicha secuencia (como el adjetivo miniinvasivas en el ejemplo [67]) como su forma simplificada (mininvasivo, en el ejemplo [68]), escritos siempre con grafía univerbal:

(67) El advenimiento de técnicas miniinvasivas para el tratamiento de la incontinencia urinaria ha permitido que las mismas sean realizadas en forma ambulatoria (ERCA: 218).

(68) [la laparoscopia] puede brindar las ventajas propias de un abordaje mininvasivo (DTL: 63).

En los casos siguientes podemos observar el mantenimiento de la secuencia anterior en otros términos, tales como antiinflamatorio y antiincontinencia:

(69) el ejercicio combinado tiene más efecto antiinflamatorio en el diabético con mayor disminución en PCR, IL-6, IL-1 $\beta$, TNF- $\alpha$, leptina y resistina y aumento en citoquinas antiinflamatorias (ETDM: 210).

(70) Se realizaron 238 procedimientos antiincontinencia (ERCA: 219).

La misma solución se ofrece para el encuentro de una secuencia - $a a$ - (con prefijos o elementos compositivos como contra- extra-, infra-, intra-, meta-, para-, supra-, tetra-, etc.; vid. OLE, cap. I, § 6.5.1.1.2) en los ejemplos (71) y (72) y en el (64) anterior, e igualmente -oo- (con auto-, dermo- electro-, endo-, gineco-, hemato-, lipo-, macro-, micro-, mono-, pro-, proto-, quimio-, retro-, etc.; vid. OLE, cap. I, § 6.5.1.1.5) en el ejemplo (73):

(71) Un metaanálisis mostró que la intensidad del ejercicio presentó mayor poder para predecir la diferencia de la HBA1C (ETDM: 204).

(72) Además, en el cáncer de pulmón izquierdo, debe añadirse la exploración de las estaciones subaórticas y paraaórtica (ATCT: 45).

(73) $[\ldots]$ tejido retroocular obtenido de pacientes con exoftalmos (FEEAH: 136).

En el corpus analizado, las documentaciones más numerosas con este tipo de encuentros vocálicos han sido las integradas por la secuencia -ee- (motivada por prefijos o elementos compositivos de origen culto tales como pre-, re- o sobre-, entre otros; vid. OLE, cap. I, § 6.5.1.1.3), para la que documentamos soluciones acertadas (74) y (75) y algunas incorrectas (76-79), por su escritura con guion:

${ }^{17}$ Nótese que esta misma documentación mantiene, además, la escritura etimológica de reemplazo, por más que a la Academia le resulte no solo válida, sino preferible (aunque minoritaria), la grafía simplificada remplazo (OLE, cap. I, § 6.5.1.1.3b).

NORMAS. REVISTA DE ESTUDIOS LINGÜÍSTICOS HISPÁNICOS, NÚMERO 3 (AÑO 2013):

http://www.uv.es/normas

(ISSN 2174-7245) 
(74) Una vez concluida la mediastinoscopia estándar [...] se alcanza a biopsar la grasa preescalénica (ATCT: 44).

(75) Las células tiroideas neoplásicas son sensibles a la insulina y a los factores de crecimiento símil insulina (IGF) I y II, sobreexpresando frecuentemente los receptores para estas sustancias (CPT: 80).

(76) [...] se decidió *re-evaluación de su cuadro clínico con nuevos análisis generales (MMRECE: 155).

(77) Dicha *re-estenosis fue identificada a los 12 meses de la cirugía, siendo tratada con una uretrotomía interna (AAIMY: 161).

(78) En el campo de la *re-estadificación después de un tratamiento de inducción, la TEMLA es una herramienta de gran precisión (ATCT: 48).

(79) La amplificación, *sobre-expresión o mutaciones somáticas del receptor están implicadas en su activación constitutiva en el desarrollo de la malignidad (FMPLM: 200).

\section{EXCEPCIONES A LA NORMA GENERAL}

Frente a la norma académica general detallada anteriormente, existen ciertas excepciones de la escritura univerbal de una voz prefijada. En algunos casos, prefijo y base se deben escribir separados por un espacio en blanco (epígrafe 3.1); en otros, ambos han de unirse mediante un guion (epígrafe 3.2).

3.1. Así pues, si la base léxica a la que el prefijo afecta es pluriverbal, ambos se escriben separados por un espacio en blanco (OLE, cap. III, § 4.1.1.2.6):

(80) El pronóstico depende fundamentalmente de la respuesta a la primer [sic] línea de tratamiento con combinaciones de drogas que incluyen antraciclinas y rituximab (anti CD-20) (TLPM: 167).

(81) En este trabajo evaluamos el antígeno recombinante SAPA (Shed Acute Phase Antigen) para la detección de anticuerpos *anti-Trypanosoma cruzi (EIAR: 177).

De esta manera, podemos considerar la escritura de (80) como correcta (aceptando el carácter pluriverbal de la combinación de una sigla y una cifra), frente a la de (81), que se consideraría errónea (ya que en este caso el prefijo modifica a la nomenclatura binomial científica que identifica una especie de protista).

3.2. Existen otras excepciones de la grafía soldada, en las que es preceptiva la escritura del prefijo con guion:

3.2.1. La primera de estas excepciones se da cuando el prefijo se une a una sigla (OLE, cap. III, § 4.1.1.2.6a), y tiene como objetivo evitar la anomalía que supondría en el sistema ortográfico del español la contigüidad de letras minúsculas y mayúsculas en interior de palabra (OLE, cap. V, $\S 2.2 .2$ ):

(82) Método inmunoturbidimétrico con partículas de latex [sic] recubiertas con anticuerpos anti-PCR (REVG: 55). 
Resultarían erróneas, pues, soluciones como las que se ofrecen a continuación:

(83) Los * microARNs ${ }^{18}$ maduros se unen a una ribonucleoproteína conformando un complejo llamado RISC (del inglés RNA induced silencing complex) (ELMA: 177-178).

(84) Existen diversos estudios que confirman la amplia participación de los *miARNs [micro ARN] en las diferentes enfermedades oncológicas (ELMA: 180).

Documentamos también el caso inverso, esto es, una sigla que funciona como elemento prefijal o sufijal, unido al componente nuclear de la expresión mediante guion:

(85) La reacción en cadena de la polimerasa-PCR [...] ha probado ser un método eficaz para detectar secuencias del cromosoma Y (ST: 197).

(86) Los pacientes con SMD presentan un incremento en el porcentaje de células Tefectoras con un perfil citotóxico y una disminución de las células T-regulatorias asociadas con la supresión de la hematopoyesis (PATNFA: 148).

3.2.2. Con la misma finalidad anterior (la de evitar el encuentro gráfico de minúscula y mayúscula en el interior de una palabra), también se escribe un guion entre una base y su prefijo cuando esta se escribe con mayúscula inicial, básicamente porque se trata de $-o$ se considera- un nombre propio (OLE, cap. III, $\S 4.1 .1 .2 .6 b$ ):

(87) El eco-Doppler es una técnica adecuada para el seguimiento sistemático de las endoprótesis aórticas (ECTE: 380 ).

(88) pre-Rituximab $(\mathrm{R})^{19}$ El tratamiento más frecuentemente empleado inicialmente en éste [sic] período fue la combinación de quimioterapia CHOP (TLPM: 167).

Este uso «separador» del guion ${ }^{20}$ se encuentra frecuentemente en la nomenclatura del lenguaje biomédico o bioquímico para separar siglas científicas que actúan como elemento prefijador -o compositivo- de determinados términos (como en las documentaciones (89) y (90), mientras que en otros casos su aparición se debe a las complejas de formulación en este lenguaje específico (91) y (92), como veremos en el siguiente punto:

${ }^{18}$ Nótese que esta escritura presenta en la sigla ARN, además, una marca incorrecta de plural consistente en la adición de una $-s$ minúscula (OLE, cap. V, § 3.3.3), solución equivocada ya que, aparte de ser un calco del inglés, está pluralizando un elemento a priori invariable, o pluralizable mediante otros mecanismos. Por otra parte, esta marca de plural para las siglas resulta muy discutida, ya que es defendida por otros autores ( $c f r$. Bezos López, 2007: 11 y 2008: 39; Martínez de Sousa, 2008: 215).

${ }^{19}$ Esta grafía anómala $*(\mathrm{R})$ es una errata muy frecuente en este tipo de textos especializados. Suele deberse a que el procesador de textos empleado (Microsoft Office Word®) tiene la opción de autocorrección desactivada. Con dicha opción activa, Word cambia automáticamente el tecleo de la combinación de teclas mencionada al símbolo de marca registrada ${ }^{\circledR}$, empleado para especificar que el término al que acompaña es el nombre de una marca comercial como, por ejemplo, un fármaco con nombre comercial patentado. Para el empleo correcto de este símbolo (pegado a la palabra a la que acompaña y situado sobre la línea de escritura del texto), vid. Aguilar Ruiz, 2013a: 112.

${ }^{20}$ Hemos de observar, como hace Bezos López (2008: 33), que la función principal del guion es la de indicar unión de elementos, frente a la de la raya (cuya función es precisamente la contraria: indicar separación). Sin embargo, en estos casos hablamos de que el guion está empleado tipográficamente para separar elementos gráficos dispares como letras mayúsculas y minúsculas.

NORMAS. REVISTA DE ESTUdios LINGÜíSTICOS HISPÁNICOS, NÚMERO 3 (AÑO 2013):

http://www.uv.es/normas

(ISSN 2174-7245) 
(89) El paciente recibió diferentes esquemas terapéuticos durante los siguientes 6 meses de su primer [sic] consulta, que incluyeron corticoides, D-penicillamida, pentoxifilina, [...] (MMRECE: 155).

(90) [...] se generan 2 metabolitos, [...] y la N-demetilbendamustina con una citotoxicidad de 5 a 10 veces menor (BENDAM: 195).

(91) La implementación del PPDj-IB preparado a partir de un aislamiento de campo de MAP [Mycobacterium avium subsp. paratuberculosis] de Argentina nos permitió demostrar que [...] su empleo permitiría la identificación de algunos animales no detectados con el antígeno convencional (OEDPP: 162).

(92) Posteriormente, desafiaron los animales y observaron que el $54 \%$ de las crías de los animales inmunizados con pCMVi-NcGRA7 y el $47 \%$ de los vacunados con pCMViNcsHSP33 fueron negativos a PCR (ADVNB: 225).

3.2.3. Otro caso en el que se debe escribir guion entre prefijo y base es en denominaciones científicas que emplean letras del alfabeto griego con valor prefijal (OLE, cap. III, § 4.1.1.2.6c). Para este tipo de términos científicos (en nuestro caso muy frecuente en investigaciones biomédicas que emplean nomenclatura química) la normativa académica pone como ejemplo una enzima, la $\alpha$-amilasa, y un tipo de anemia hereditaria, la $\beta$-talasemia (debida a un déficit en las síntesis de cadenas beta de aminoácidos que componen la hemoglobina). Bezos López (2008: 100) especifica, además, que estas letras griegas deben escribirse en letra redonda (frente a otros elementos prefijales, que se suelen escribir en cursiva). Así, por ejemplo, en nuestro corpus encontramos:

(93) [...] se indujo su diferenciación a osteoblastos usando un medio de diferenciación conteniendo $25 \mathrm{mg} / \mathrm{ml}$ de ácido ascórbico y $5 \mathrm{mM}$ de $\beta$-glicerolfosfato durante $0,15 \mathrm{o}$ 21 días (DAPOCP: 72).

(94) Todos contribuyen a una producción excesiva de progesterona (P4), 17 $\alpha$ hidroxiprogesterona y testosterona (MHCSOP: 84).

Tal y como especifica este mismo autor (2008: 98-9), los prefijos empleados en los nombres sistemáticos de la nomenclatura química han de escribirse separados con guion $^{21}$ (y normalmente en cursiva); debido a la gran complejidad de las normas de dicha nomenclatura, se documenta gran variedad de alternancias (con posposiciones del prefijo):

(95) Luego, la aplicación del ensayo de la trans-sialidasa (TIA) en perros mostró una copositividad [sic] con el xenodiagnóstico del $97 \%$ (EIAR: 180).

(96) El presente estudio muestra que el $24 \%$ de los pacientes pos-ATC tratados con clopidogrel presentaron HPR [hiperreactividad plaquetaria residual] o resistencia al tratamiento (TAPFP: 356).

(97) [...] incluyendo especialmente al Factor de Necrosis Tumoral-alfa (Tumor Necrosis Factor-alpha: TNF $\alpha$ ) (PATNFA: 148).

(98) El genotipo -308 A/A17 y el alelo -308 A18 del TNF $\alpha$ fueron encontrados sobrerepresentados [sic] en pacientes con SMD [síndromes mielodisplásicos] (PATNFA: 148).

${ }^{21}$ Como observa el mismo Bezos López (2008: 98), constituyen una excepción los prefijos de sentido multiplicativo (como bi-, tri-, etc.), que se escriben soldados gráficamente a su base léxica.

NORMAS. REVISTA DE ESTUdIOS LINGÜÍSTICOS HISPÁNICOS, NÚMERO 3 (AÑO 2013):

http://www.uv.es/normas

(ISSN 2174-7245) 
(99) el ejercicio combinado tiene más efecto antiinflamatorio en el diabético con mayor disminución en PCR, IL-6, IL-1 $\beta$, TNF- $\alpha$, leptina y resistina y aumento en citoquinas antiinflamatorias (ETDM: 210).

(100) Las células inmunes activadas podrían sensibilizar a través de la liberación de TNF-a e IL-1b a las células tiroideas (ATMPTH: 142).

(101) En cambio varios estudios mostraron una falta de asociación del polimorfismo del ERalfa y el riesgo cardiovascular (REVG: 59).

Básicamente, esta misma norma se habría de seguir en la escritura de formulaciones químicas formadas por otros elementos que, al igual que las letras griegas, funcionan como prefijos (vid. Bezos López, 2008: 98 y ss.):

(102) La hipermetilación aberrante del promotor de e-cadherina lleva a la subexpresión de esta molécula y contribuye con la patogénesis de la LMA [leucemia mieloide aguda] (ELMA: 180).

Por otro lado, para la expresión de estos términos científicos con letras griegas prefijadas, la Academia contempla otras dos soluciones (OLE, cap. III, § 4.1.1.2.6c). Una de ellas es la posibilidad de representar estas letras griegas como especificadores pospuestos, esto es, mediante la posposición de la letra griega, separada por un espacio en blanco (amilasa $\alpha$, talasemia $\beta$ ). La segunda sería la sustitución de la letra griega por su nombre en español, usada como prefijo y unida a la base léxica sin guion $(\text { alfaamilasa, betatalasemia })^{22}$.

3.2.4. Cuando el término que se desea expresar resulta ser un vocablo constituido por la combinación de letras y cifras, OLE (cap. III, § 4.1.1.2.7) observa que ambas partes se han solido separar tradicionalmente mediante un guion, independiente de su ordenación, es decir, letra-cifra (ejemplos 103 y 104) o viceversa (105), lo que constituye la tercera excepción:

(103) La presencia del alelo-308 A se asoció con menor edad, mayor grado de anemia y trombocitopenia al diagnóstico (PATNFA: 151).

(104) Además, el gen Oct-4 ha sido implicado en la tumorigénesis de células germinales adultas (ST: 198).

${ }^{22}$ Sin embargo, tal como analiza Bezos López (2012), ninguna de las dos alternativas anteriores parece muy acertada. Así, respecto a la primera opción, la escritura de amilasa $\alpha$ para el caso del nombre de la enzima no podría resultar enteramente correcto si la ordenación de sus componentes depende del orden de la nomenclatura química, ya que este está fijado, sigue unas normas estrictas y no hay posibilidad de variación Bezos López (2008: 97 y ss.); sin embargo, el DTM (s. v. amilasa) sí contempla la posibilidad de esta escritura. Quizá más discutible resultaría la expresión de talasemia $\beta$, ya que para el DTM esta escritura resulta más acertada: al ser uno de los tipos de dicho trastorno hemático (frente a la tipo $\alpha$ ), la letra griega funciona como aposición especificativa. Además, empleadas con esta función apositiva, no es infrecuente encontrar las letras griegas desarrolladas con su nombre en español (como talasemia alfa y talasemia beta, en MERCK 2005: 1278-9); lo mismo cabría decir del término factor de necrosis tumoral alfa documentado en el ejemplo anterior número (97) (frente al factor de necrosis tumoral beta o linfotoxina). Por lo que respecta a segunda alternativa, Bezos López (2012) la contempla como una opción «de emergencia», para cuando el autor no disponga de la fuente griega, pero observa que en tal caso se debería respetar el guion (alfa-amilanasa) (vid. Aguilar Ruiz, 2013a: 104 y 118).

NORMAS. REVISTA DE ESTUdios LINGÜíSTICOS HISPÁNICOS, NÚMERO 3 (AÑO 2013):

http://www.uv.es/normas

(ISSN 2174-7245) 
(105) La azacitidina (5-aza) y la decitabina son dos potentes agentes inhibidores de las DNMTs, interrumpiendo su interacción con el ADN (ELMA: 181). ${ }^{23}$

No obstante, la misma preceptiva académica (OLE, cap. III, § 4.1.1.2.7) prefiere prescindir de este guion en el caso en el que el vocablo esté compuesto por una sigla (en letras mayúsculas o versales) y una expresión numérica (en cifras), de modo que, aunque no resulte incorrecto, se preferiría la escritura de $S N P 308$ a $S N P-308$ en el siguiente ejemplo:

(106) La detección del SNP-308 G/A del TNF $\alpha$ podría ser útil para futuros ensayos clínicos, particularmente aquellos que bloqueen o modulen la actividad de esta citoquina proinflamatoria (PATNFA: 152).

Si bien el tipo de expresiones anteriores se está extendiendo mucho en ámbitos como el político o el tecnológico ${ }^{24}$, habría que revisar si esta normativa sería válida en el campo de la nomenclatura en biomedicina y bioquímica, que siguen sus propias reglas y el guion puede ser significativo (vid. Bezos López, 2008: 98 y ss.).

3.2.5. La Academia especifica que, de manera excepcional, un guion también puede escribirse para separar el prefijo de su base léxica si lo que se desea es:

a) Enfatizar el valor semántico del prefijo (OLE, cap. III, § 4.1.1.2.6e). Esta escritura con guion se permite, pues, como recurso gráfico para llamar la atención sobre la pieza léxica prefijada, como en los términos re-recidiva y re-reoperar en (107) y (108):

(107) Cuando la recidiva de vía anterior es tratada con las técnicas de Wantz o de Stoppa, la re-recidiva es del $1 \%$, bastante inferior a la señalada por Rutkow (PAVPPA).

(108) otros [pacientes] no alcanzan esos porcentajes, pues con la primera [la técnica quirúrgica de Wantz] tienen el $7.7 \%$ de recidivas y el $27.7 \%$ después de re-reoperarlas (PAVPPA).

b) Para favorecer la correcta interpretación del término cuando este, sin la escritura del guion, puede interpretarse con un significado distinto al que se desea transmitir (OLE, cap. III, § 4.1.1.2.6e), como en el ejemplo propuesto por la Ortografía:

(109) Ambos cirujanos co-operan los jueves por la tarde (OLE, cap. III, § 4.1.1.2.6e),

ya que el significado que el autor pretendería transmitir aquí no es el del verbo cooperar 'obrar juntamente con otro u otros para un mismo fin' (DRAE), sino el de, podríamos decir, 'realizar [dos o más cirujanos] a la vez una misma operación quirúrgica a un

\footnotetext{
${ }^{23}$ Sobre el uso incorrecto de una $-s$ final como marca del plural de la sigla $D N M T$ en este ejemplo, vid. nota 18.

${ }^{24}$ Así, los ejemplos que la Ortografía (cap. III, § 4.1.1.2.7) ofrece son G20 (por grupo de los 20), MP4 (por Moving Picture Experts Group version 4) y telefonía $3 G$ (por de tercera generación).
}

NORMAS. REVISTA DE ESTUdIOS LINGÜÍSTICOS HISPÁNICOS, NÚMERO 3 (AÑO 2013):

http://www.uv.es/normas

(ISSN 2174-7245) 
mismo paciente' (co-operar), por lo que opta por marcarlo gráficamente con la escritura de un guion.

3.2.6. Puede darse, además, la necesidad de coordinar dos o más prefijos en una misma palabra (OLE, cap. III, § 4.1.1.2.6f). Este caso se da con la coordinación de dos (o más) voces prefijadas coordinadas, formadas sobre una misma base léxica. Los prefijos que queden desgajados de la base se deben escribir con un guion pospuesto; de esta manera se indica que «no se trata de palabras autónomas, sino de segmentos afijos, que deben interpretarse semánticamente reponiendo la base léxica que les falta, la misma que aparece en el último término de la coordinación» (OLE, cap. $\mathrm{V}, \S$ 2.2.2.4.). Un ejemplo lo vemos en la siguiente documentación, donde se coordinan los elementos radio- y quimio- con la base terapia:

(110) Sólo [sic] fueron incluidos pacientes con diagnóstico confirmado de SMD de novo, sin antecedentes documentados de radio- o quimioterapia (PATNFA: 148).

Por lo tanto, se consideran erróneas las escrituras de los prefijos separados por un espacio en blanco y sin guion, como en los siguientes casos (sobre todo el número [113], en el que se presentan no uno sino dos prefijos separados de su base léxica):

(111) De esta manera, la histona *hipo o hiperacetilada interactúa de manera diferente con el promotor que afecta y el gen regulado se puede expresar en más o en menos (ELMA: 180).

(112) Se realizó hidratación parenteral y preparación intestinal con fosfato *mono y disódico (CNILH: 241).

(113) Se indicaba a viva voz en 3 distintos momentos operatorios (*pre, *intra y *postoperatorio inmediato) (ILVCS: 13).

(114) [el bridging] manejado de manera no adecuada, tampoco estará exento del riesgo de sangrado *intra y *post operatorio (RITAPPI: 186).

Una de las explicaciones a esta excepción se debe a la posible concepción de este hecho mediante la consideración de que en estos grupos nominales lo que se coordinan son los adjetivos, y no los prefijos (vid. NGLE, § 10.3.3).

Por otro lado, se documentan casos de coordinación de prefijos con sintagmas más complejos, como el siguiente:

(115) Los resultados medidos en número de paños *pre de 3,1 y postcirugía [sic] de 0,4 promedio, resultaron similares al de los implantes de esfínteres artificiales (ERCA: 225).

La anómala construcción de la frase se debe a una mala redacción. Una de las posibles soluciones (manteniendo la coordinación de ambos prefijos, para ilustrar la norma que aquí comentamos) podría haber sido la que ofrecemos en (116):

(116) Los resultados medidos en número de paños (con un promedio de 3.1 y 0.4 en la pre- y poscirugía, respectivamente), resultaron similares al de los implantes de esfínteres artificiales (ERCA: 225).

NORMAS. REVISTA DE ESTUDIOS LINGÜÍSTICOS HISPÁNICOS, NÚMERO 3 (AÑO 2013):

http://www.uv.es/normas

(ISSN 2174-7245) 
3.3. Existe, por último, una palabra a la que se le puede atribuir cierto uso prefijal pero que, sin embargo, no se escribe soldada a su base ni unida con guion, sino separada por un espacio; se trata del adverbio de negación no antepuesto a un sustantivo (OLE, cap. $\mathrm{V}, \S$ 2.2.2.2). La normativa académica justifica esta decisión ortográfica en la tonicidad que mantiene el adverbio en este tipo de expresiones, por lo que no se ha de escribir como vocablo independiente en este tipo de expresiones, aun cuando sea rastreable un uso cuasiprefijal en las construcciones no infectados, no iónicos, no diabéticos, etc. siguientes:

(117) Esta respuesta de estimulación frente a PPD en animales no infectados ya ha sido comunicada previamente (OEDPP: 162).

(118) [En la tabla 1] emulsión de copolímeros no iónicos (ADVNB: 219).

(119) El tratamiento con metformina no modificó significativamente la insulinemia, tanto en animales diabéticos como no diabéticos (DAPOCP: 73).

(120) En nuestro estudio, las mujeres homocigotas, representadas por todos los haplotipos no 1A, solo exhiben aumento en triglicéridos séricos ( $R E V G$ : 59).

En este tipo de textos científicos, una construcción muy recurrente con el adverbio de negación no como componente prenuclear es la de linfoma no Hodgkin, empleada para denominar un tipo de diversos cánceres que se desarrollan en los linfocitos B o T. Si bien esta expresión -escrita sin guion, como establece la norma- prolifera en nuestro corpus, en la redacción médica en español sería más correcta la escritura de linfoma no hodgkiniano, al tratarse la primera de un calco innecesario del inglés non-Hodgkin lymphoma:

(121) Caso clínico: varón de 44 años, diagnosticado en enero de 2011 de linfoma no Hodgkin tipo T no especificado (BFACS: 170).

(122) [...] CD3 para las células T, CD20 por las células B y CD43 para linfoma no Hodgkin (SMIP: 164).

(123) El LPM [linfoma primario de mediastino] es un linfoma de células grandes originado en los linfocitos B del timo, constituye el 2-3\% de los linfomas no Hodgkin (LNH) del adulto (TLPM: 166).

(124) [la bendamustina] no presenta resistencia cruzada con otros citotóxicos, demostrando actividad frente a Linfomas No Hodgkin (BENDAM: 195).

La escritura -errónea- con guion de las formas evitables linfoma no-Hodgkin/no Hodgkin frente a la preferible linfoma no hodgkiniano se debe al influjo de las publicaciones en inglés, ya que esta lengua el elemento non- tiene un funcionamiento muy productivo como prefijo. No obstante, en el corpus estudiado no se han encontrado dichas escrituras con guion, tratándose de una grafía muy recurrente en otros textos científicos con los que hemos trabajado. 


\section{CONCLUSIONES}

A lo largo del presente trabajo hemos ido comentando detalladamente la normativa académica relativa a la prefijación en términos científicos especializados, ofreciendo diversos ejemplos reales y cercando nuestro corpus de estudio al ámbito geográfico de las publicaciones científicas en Argentina. De manera recapitulatoria, ofrecemos un sumario de la doctrina académica aquí especificada, que sirve como conclusión de nuestro trabajo:

La normativa académica reconoce como norma general que la escritura preceptiva de una base léxica prefijada sea la unitaria, esto es, que prefijo y base se escriban soldados gráficamente, de modo que se presente una grafía univerbal (anticoagulación, intraperitoneal, coactivador, reanastomosis). Una innovación que se debe tener en cuenta es el caso especial de las voces prefijadas por el afijo $\operatorname{pos}(t)-$, ya que la nueva Ortografía «recomienda» la variante gráfica simplificada pos- (esto es, sin su - $t$ final) si la base que prefija comienza tanto por vocal (posoperatorio, posinoculación) como por consonante (posparto, poscirugía, posquirúrgico), aunque en este último caso se reconocen ciertas excepciones: 1) cuando la base prefijada empieza por la consonante $s$ (posepticemia, posobredosis), para evitar, con la eliminación de la grafía $t$, la secuencia resultante $-s s-; 2$ ) cuando comienza por la consonante $t$ - (postraumático), donde se reduce la geminación gráfica de dos tes (gráficamente, -tt-) originada por el encuentro de ambas (en nuestro ejemplo, post + traumático). En el léxico especializado científico es preferible que prefijo y base se escriban unidos gráficamente incluso cuando la vocal final del prefijo y la inicial de la base originen el encuentro de dos vocales idénticas (metaanálisis, antiinflamatorio, retroocular) o las sílabas final e inicial de ambos, cuando estas resulten ser la misma, ocasionen una geminación (antitimocito).

No obstante, se reconocen ciertas excepciones a esta norma. La primera es que prefijo y base se separan mediante un espacio en blanco cuando la base sea de carácter pluriverbal (anti Trypanosoma cruzi, pre tinción de Gram) o el «prefijo» sea el adverbio de negación no con sentido negativo o privativo (linfoma no hodgkiniano, paciente no inmunodeprimido, copolímeros no iónicos). En la segunda se reconocen una serie de excepciones que prescriben la unión de prefijo y base léxica mediante un guion, como cuando el prefijo se une a una sigla (anti-PCR, micro-ARN), a una cifra (alelo-308, gen Oct-4) o a una base cuya letra inicial se escribe con mayúscula, normalmente por tratarse de un nombre propio, como puede ser el caso de un antropónimo que forma parte del nombre de síndromes o trastornos (anti-Pickwick, pre-Münchhausen). También es preceptiva la escritura con guion cuando una nomenclatura química cuenta con una letra griega que actúa como prefijo ( $\alpha$-amilasa, $\beta$-glicerofosfato) o cuando se presentan ciertas estructuras que coordinan varios prefijos a una misma base (radio- $o$ quimioterapia; pre-, intra- y posoperatorio) y, excepcionalmente, cuando se desea llamar la atención sobre la pieza léxica prefijada (re-reoperación, re-recidiva) o para favorecer la correcta interpretación del término cuando este, sin la escritura del guion, pudiera interpretarse con un significado distinto al empleado en el texto (co-operar 'realizar [dos o más cirujanos] a la vez una misma operación quirúrgica a un mismo paciente', distinto de cooperar 'obrar juntamente con otro u otros para un mismo fin'). 
Este conjunto de normas aquí compendiado ha sido el que se ha ido documentado a lo largo del artículo. Gracias a este, podemos comprobar que, dos años después de la publicación de la nueva ortografía académica, las publicaciones de carácter científicomédico en lengua española siguen presentando aún lo que podríamos calificar de serias carencias normativas lingüístico-ortotipográficas (incorrecciones y empleos impropios de la ortotipografía - e incluso de la ortografía - que propugna la normativa académica respecto a la prefijación). Sus principales causas son, fundamentalmente, tanto el desconocimiento de la normativa $-\mathrm{y}$ de las recientes innovaciones- por parte de los profesionales médico-quirúrgicos que redactan trabajos científicos, como la gran cantidad de anglicismos innecesarios (léxicos, morfológicos, ortotipográficos, etc.) diseminados en la investigación científica en español, debido a la enorme influencia que ejerce la lengua inglesa en este tipo de publicaciones. Como concluíamos en el trabajo que fue el origen de la presente investigación (Aguilar Ruiz, 2012: 32-3), nos parece fundamental, por parte del profesional de las ciencias de la salud que redacte y divulgue trabajos científicos, no solo un conocimiento profundo de la lengua española (una tarea individual) sino también la voluntad de unificar los criterios ortográficos, ortotipográficos, etc., en todo el ámbito panhispánico (una labor colectiva), por la importancia que tiene este tipo de publicaciones «para la transmisión y el progreso del conocimiento científico humano, $[\ldots]$ en las que el cuidado de la expresión y la corrección lingüística han de ser extremos, ya que en ellas no ha de caber lugar para equívocos, imprecisiones e incorrecciones, y juegan un papel primordial en la formación científica de futuras generaciones de profesionales sanitarios» (Aguilar Ruiz, 2012: 32).

\section{REFERENCIAS BIBLIOGRÁFICAS}

Aguilar Ruiz, Manuel José (2012): «El empleo de las nuevas normas ortotipográficas de la lengua española en publicaciones científicas médicas», Normas. Revista de Estudios Lingüísticos Hispánicos, 2, 7-43.

AgUILAR RUIZ, Manuel José (2013a): «Las normas ortográficas y ortotipográficas de la nueva Ortografía de la lengua española (2010) aplicadas a las publicaciones biomédicas en español: una visión de conjunto», Panace@. Revista de Medicina, Lenguaje $y$ Traducción, 14, 37: 101-120 [en línea]: <http://www.tremedica.org/panacea/IndiceGeneral/n37-tribuna-MJAguilarRuiz.pdf>. [Consulta: 01/09/2013].

Aguilar Ruiz, Manuel José (2013b): «Tinción de Gram y bacterias gram positivas y gram negativas. Una observación a la propuesta de escritura -y traducciónde la normativa académica», Puntoycoma. Boletín de los traductores españoles de las instituciones de la Unión Europea [en línea]: <http://ec.europa.eu/translation/bulletins/puntoycoma/133/pyc_133.pdf> [Consulta: 01/09/2013].

BEzos LóPEZ, Javier (2008): Tipografía y notaciones científicas, Gijón, Trea. 
Bezos LóPez, Javier (2011): La ortografía académica del 2010. Comentarios sobre la última edición de la obra [en línea]: <http://www.textipografia.com/ortografia_academias_2010.html> [Consulta: 02/09/2013].

BEzos LóPEZ, Javier (2012): Las notaciones científicas en la Ortografía académica [en línea]: <http://www.tex-tipografia.com/ortografia_notaciones.html>. [Consulta: 01/09/2013].

Claros, Gonzalo (2008): «Un poco de estilo en la traducción científica: aquello que quieres conocer pero no sabes dónde encontrarlo», Panace@. Revista de Medicina, Lenguaje $y \quad$ Traducción, 9, 28 [en línea]: 145-158. <http://www.medtrad.org/panacea/IndiceGeneral/n28_revistilo-claros.pdf>. [Consulta: 01/09/2013].

DE LA RIVA ForT, José Antonio (2011): «Utilidad de la nueva Ortografía de la lengua española para el profesional del lenguaje», Panace@. Revista de Medicina, Lenguaje $y$ Traducción, 12, 33, 129-137 [en línea]: <http://www.medtrad.org/panacea/IndiceGeneral/n33-Resenas-Fort.pdf> [Consulta: 01/09/2013].

MARTíNEZ DE SOUSA, José (2008a): Ortografía y ortotipografía del español actual (2. ${ }^{a}$ ed.), Gijón, Trea.

REAl ACADEMIA ESPAÑOla (2001): Diccionario de la lengua española (22. ${ }^{\mathrm{a}} \mathrm{ed}$.), Madrid, Espasa. Avance de la 23. a ed [en línea]: 〈www.rae.es/rae.html〉.

REAL ACADEMIA ESPAÑOla y ASOCIACIÓN DE ACADEMIAS DE LA LENGUA ESPAÑOLA (2005): Diccionario panhispánico de dudas (DPD), Madrid, Santillana. Edición en línea: <http://lema.rae.es/dpd/>.

REAL ACADEMIA ESPAÑOla y ASOCIACIÓN DE ACADEMIAS DE LA LENGUA ESPAÑOLA (2010): Nueva gramática de la lengua española (NGLL) (Manual), Madrid, Espasa.

REAl ACADEMIA ESPAÑola y ASOCIACión DE ACADEMIAS DE LA LENGUA ESPAÑOLA (2010): Ortografía de la lengua española (OLE), Madrid, Espasa.

ReAl ACADEMIA NACIONAL DE MEDICINA (2011): Diccionario de términos médicos. Madrid: Editorial Médica Panamericana. Disponible (con acceso restringido) en línea: <http://dtme.ranm.es/>. [Consulta: 01/09/2013].

VV. AA. (2005): Manual Merck de información médica para el hogar, Barcelona, Océano [en línea]: <www.msd.es/publicaciones/mmerck_hogar/>. [Consulta: 01/09/2013].

\section{PUBLICACIONES CIENTÍFICAS CITADAS}

(AAIMY) CAPIEL, Leandro et al. (2012): «Anastomosis ampliada con injerto de mucosa yugal en el tratamiento de la estrechez de la uretra bulbar», Revista Argentina de Urología, 77, 3, 158-165 [en línea]:

<http://www.revistasau.org/index.php/revista/article/view/3320/3264>. [Consulta: 03/03/2013]. 
(ACAS) ANGUlo, Pablo E. et al. (2012): «Adenocarcinoma en células en anillo de sello. Un raro subtipo de cáncer de vesícula biliar», Revista Argentina de Cirugía, 102, 77-79 [en línea]: <http://www.scielo.org.ar/scielo.php?pid=S2250639X2012000200006\&script=sci_arttext $>$. [Consulta: 04/03/2013].

( $A D V N B)$ HECKER, Yanina P. et al. (2012): «Avances en el desarrollo de vacunas contra la neosporosis bovina», Revista Argentina de Microbiología, 44, 3, 216-230 [en línea]: $<$ http://www.scielo.org.ar/scielo.php?pid=S032575412012000300014\&script=sci_arttext $>$. [Consulta: 08/03/2013].

(AP) PIERINI, Ángel L. et al. (2012): «Actinomicosis pélvica», Revista Argentina de Cirugía, 102, 74-76 [en línea]: <http://www.aac.org.ar/revista/2012/102/Abril-MayoJunio/6.pdf>. [Consulta: 08/03/2013].

(ATCT) RAMI PORTA, Ramón et al. (2012): «El acceso transcervial en cirugía torácica: indicaciones actuales y resultados», Revista Argentina de Cirugía, 102, 43-56 [en línea]: <http://www.scielo.org.ar/scielo.php?script=sci_arttext\&pid=S2250639X2012000200001>. [Consulta: 08/03/2013].

(ATMPTH) AstaRITA, G. et al. (2012): «Autoinmunidad tiroidea: Mecanismos patogénicos comunes y distintivos en tiroiditis de Hashimoto y enfermedad de Graves», Revista Argentina de Endocrinología y Metabolismo, 49, 3, 138-144 [en línea]: <http://www.raem.org.ar/numeros/2012/3/138-144-ENDO3-6_Astarita.pdf>. [Consulta: 04/03/2013].

(BCIDPA) MÉNDIZ, Óscar A. et al. (2012): «Beneficios y complicaciones del implante directo de prótesis aórtica autoexpandible para el tratamiento de la estenosis valvular aórtica grave», Revista Argentina de Cardiología, 80, 360-365 [en línea]: $<$ http://www.scielo.org.ar/scielo.php?script=sci_arttext\&pid=S1850-

37482012000500007>. [Consulta: 04/03/2013].

(BENDAM) BEZARES, R. F. et al. (2012): «Bendamustina», Hematología, 16, 3, 193-199 [en línea]: <http://www.sah.org.ar/revista/numeros/vol16-n3-192-199.pdf>. [Consulta: 03/03/2013].

(BFACS) GARCíA, Tomás et al. (2012): «Bacteriemia fulminante asociada a Capnocytophaga sputigena en un paciente con linfoma no Hodgkin tipo T. Diagnóstico por secuenciación genética del ARNr 16S», Revista Argentina de Microbiología, 44, 3, 170-172 [en línea]: <http://www.redalyc.org/articulo.oa?id=213025111007>. [Consulta: 08/03/2013].

(CNILH) CHERNOBILSKY, Víctor et al. (2012): «Cistectomía con neovejiga ileal ortotópica en el hombre: técnica quirúrgica, manejo del perioperatorio y de las complicaciones», Revista Argentina de Urología, 77, 4, 238-255 [en línea]: <http://www.revistasau.org/index.php/revista/article/view/3340>. [Consulta: 04/03/2013].

(CPT) D'ADDINO, J. L. et al. (2012): «Carcinoma papilar tiroideo variante esclerosante difuso», Revista Argentina de Endocrinología y Metabolismo, 49, 2, 77-81 [en línea]: <http://www.scielo.org.ar/scielo.php?pid=S185130342012000200004\&script=sci_arttext $>$. [Consulta: 08/03/2013].

(CR) EsCARAIN, María C. et al. (2012): «Cirugía de Ross: 15 años de experiencia», Revista Argentina de Cardiología, 80, 347-353 [en línea]: 
$<$ http://www.scielo.org.ar/scielo.php?pid=S1850-

37482012000500005\&script=sci_arttext >. [Consulta: 08/03/2013].

(CTR) GONZÁLEZ, Osvaldo et al. (2012): «Cáncer tiroideo recurrente. Diagnóstico, tratamiento y riesgo de supervivencia», Revista Argentina de Cirugía, 102, 22-27 [en línea]: $<$ http://www.scielo.org.ar/scielo.php?pid=S2250639X2012000100004\&script=sci_arttext $>$. [Consulta: 04/03/2013].

(DAPOCP) TOLOSA, M. J. et al. (2012): «La diabetes altera el potencial osteogénico de células progenitoras de médula ósea. Efectos del tratamiento con metformina», Revista Argentina de Endocrinología y Metabolismo, 49, 2, 70-76 [en línea]: $<$ http://www.scielo.org.ar/scielo.php?script=sci_arttext\&pid=S185130342012000200003 >. [Consulta: 03/03/2013].

(DTL) MAZZA, Osear et al. (2012): «Duodenopancreatectomía totalmente laparoscópica. Consideraciones técnicas y aplicabilidad inicial en un centro de alto volumen de cirugía pancreática», Revista Argentina de Cirugía, 102, 62-68 [en línea]: $<$ http://www.scielo.org.ar/scielo.php?pid=S2250-

639X2012000200003\&script=sci_arttext $>$. [Consulta: 04/03/2013].

$(E A D F H)$ SolOAGA, Rolando N. et al. (2012): «Evaluación del antibiograma directo desde el frasco de hemocultivo con el sistema Vitek 2C: su utilidad en la clínica», Revista Argentina de Microbiología, 44, 3, 165-169 [en línea]: $<$ http://www.scielo.org.ar/scielo.php?pid=S0325-

75412012000300006\&script=sci_arttext $>$. [Consulta: 03/03/2013].

(ECTE) Agostino, Silvia V. et al. (2012): «Endofuga: complicación del tratamiento endovascular del aneurisma de la aorta abdominal», Revista Argentina de Cardiología, 80, $380 \quad$ [en $<$ http://www.scielo.org.ar/scielo.php?script=sci_arttext\&pid=S185037482012000500010>. [Consulta: 04/03/2013].

(EGNCA) VAN DER KOOY, Ernesto et al. (2012): «Estimación del gasto necesario para garantizar la canasta asistencial del PMO», Médicos, 71, 30-34 [en línea]: <http://www.revistamedicos.com.ar/numero71/medicos71.pdf >. [Consulta: 03/03/2013].

(EIAR) CIMINO, Rubén O. et al. (2012): «Evaluación inmunoenzimática del antígeno recombinante SAPA en perros infectados naturalmente por Trypanosoma cruzi», Revista Argentina de Microbiología, 44, 3, 177-181 [en línea]: $<$ http://www.scielo.org.ar/scielo.php?pid=S0325-

75412012000300009\&script=sci_arttext $>$. [Consulta: 03/03/2013].

(ELMA) BÉGUELIN KEHOE Pedro et al. (2012): «Epigenética en Leucemia Mieloide Aguda», Hematología, 16, 3, 176-184 [en línea]: <http://www.sah.org.ar/revista/numeros/vol16-n3-176-184.pdf>. [Consulta: 03/03/2013].

(ERCA) GARRIDO, Gustavo et al. (2012): «Evaluación de los resultados de la cirugía antiincontinencia en un centro de cirugía ambulatoria», Revista Argentina de Urología 77, 4, 218-228 [en <http://www.revistasau.org/index.php/revista/article/view/3338>. [Consulta: 04/03/2013]. 
(ETDM) MÁRQUEZ, Jaime Jorge et al. (2012): «El ejercicio en el tratamiento de la diabetes mellitus tipo 2», Revista Argentina de Endocrinología y Metabolismo, 49, 4, 203-212 [en línea]: <http://www.scielo.org.ar/pdf/raem/v49n4/v49n4a06.pdf>. [Consulta: 03/03/2013].

(ETINPL) RozANEC, José J. et al. (2012): «Evolución del tiempo de isquemia en 130 nefrectomías parciales laparoscópicas», Revista Argentina de Urología, 77, 3, 184190 [en línea]: <http://www.revistasau.org/index.php/revista/article/view/3323>. [Consulta: 08/03/2013].

(EUAT) VIRASORO, Ramón et al. «Esfínter urinario artificial transcorpóreo: ¿un recurso válido para el tratamiento de la incontinencia de orina post-prostatectomía radical?», Revista Argentina de Urología, 77, 3, 166-175 [en línea]: <http://www.revistasau.org/index.php/revista/article/view/3321>.

(FEEAH) PISAREV, M. A. (2012): «Fisiopatología del exoftalmos endocrino. Aspectos históricos», Revista Argentina de Endocrinología y Metabolismo, 49, 3, 134137 [en línea]: <http://www.scielo.org.ar/scielo.php?script=sci_arttext\&pid=S185130342012000300005>. [Consulta: 04/03/2013].

(FMPLM) DOURISBOURE, R. (2012): «Factores moleculares pronóstico en leucemia mieloide aguda: detección de mutaciones en FLT3, NPM1 y CEBPA», Hematología, 16, 3, 200-202 [en línea]: <http://www.sah.org.ar/revista/numeros/vol16-n3-200202.pdf>. [Consulta: 03/03/2013].

(ILVCS) ARriBAlZAGA, Eduardo B. et al. (2012): «Implementación del listado de verificación de cirugía segura», Revista Argentina de Cirugía, 102, 12-16 [en línea]: $<$ http://www.scielo.org.ar/scielo.php?pid=S2250-

639X2012000100002\&script=sci_arttext $>$. [Consulta: 04/03/2013].

(MHCSOP) SABÁN, M. et al. (2012): «Metabolismo de los hidratos de carbono en el síndrome de ovario poliquístico», Revista Argentina de Endocrinología y Metabolismo, 49, 2, 82-87 [en <http://www.scielo.org.ar/scielo.php?script=sci_arttext\&pid=S1851-

30342012000200005>. [Consulta: 08/03/2013].

(MMRECE) QUIROGA, Luis et al. (2012): «Mieloma Múltiple asociado a una rara esclerosis cutánea, el Escleredema», Hematología, 16, 3, 154-161 [en línea]: <http://www.sah.org.ar/revista/numeros/vol16-n3-154-161.pdf>.

[Consulta: 04/03/2013].

(MND) RuIZ, Claudio A. et al. (2012): «Mediastinitis necrotizante descendente: dieciséis años de experiencia», Revista Argentina de Cirugía, 102, 7-11 [en línea]: $<$ http://www.scielo.org.ar/scielo.php?pid=S2250-

639X2012000100001\&script=sci_arttext>. [Consulta: 03/03/2013].

(MPUM) POLO LÓPEZ, Carlos Álvaro et al. (2012): «Melanoma primario de uretra masculino. Revisión de la literatura a propósito de un caso», Revista Argentina de Urología, 77, 4, 262-265 [en línea]: <http://www.revistasau.org/index.php/revista/article/view/3343>. [Consulta: 03/03/2013].

(OEDPP) GIOFFRÉ, Andrea et al. (2012): «Obtención y evaluación de un derivado proteico purificado de una cepa argentina de Mycobacterium avium subsp. Paratuberculosis», Revista Argentina de Microbiología, 44, 3, 155-164 [en línea]: 
<http://www.scielo.org.ar/scielo.php?script=sci_arttext\&pid=S0325-

75412012000300005>. [Consulta: 03/03/2013].

(PAVPPA) DÁVILA DORTA, David (en prensa): «Prótesis autoadhesiva por vía preperitoneal posterior abierta (Nyhus modificado-técnica personal) en el tratamiento de las hernias de la ingle», Revista Hispanoamericana de Hernia, 4.

(PATNFA) BELli, Carolina B. et al. (2012): «La presencia del alelo -308 A del $\mathrm{TNF} \alpha$ se asocia con anemia y plaquetopenia en pacientes con Síndromes Mielodisplásicos», Hematología, 16, 3, 147-153 [en línea]: <http://www.sah.org.ar/revista/numeros/vol16-n3-147-153.pdf>. [Consulta: 08/03/2013].

(PCA) FISZLEJDER, León et al. (2012): «Patología cardiovascular en la acromegalia», Revista Argentina de Endocrinología y Metabolismo, 49, 3, 124-133 [en línea]: $\quad<$ http://www.scielo.org.ar/scielo.php?script=sci_arttext\&pid=S185130342012000300004>. [Consulta: 08/03/2013].

(REVG) RAUSCHEMBERGER, María Belén et al. (2012): «Receptor de estrógenos: variantes genéticas del ESR1 y parámetros bioquímicos de riesgo cardiovascular», Revista Argentina de Endocrinología y Metabolismo, 49, 2, 53-61 [en línea]: <http://www.scielo.org.ar/pdf/raem/v49n2/v49n2a01.pdf>. [Consulta: 03/03/2013].

(RIPEC) ESTEVA, Hugo (2012): «Reflexiones irreverentes sobre el paternalismo y la evidencia en cirugía», Revista Argentina de Cirugía, 102, 69-73 [en línea]: $<$ http://www.scielo.org.ar/scielo.php?script=sci_arttext\&pid=S2250639X2012000200004>. [Consulta: 04/03/2013].

(RITAPPI) ALTMAN, Raúl et al. (2012): «Recomendaciones para la interrupción de la terapéutica anticoagulante en el peri-operatorio y procedimientos invasivos», Hematología, 16, 3, 185-192 [en línea]: <http://www.sah.org.ar/revista/numeros/vol16n3-185-192.pdf>. [Consulta: 05/03/2013].

(SMIP) FERRARO, C. et al. (2012): «Sarcoma Mieloide de Intestino en pediatría: Reporte de un caso y revisión de la literatura», Hematología, 16, 3, 162-165 [en línea]: <http://www.sah.org.ar/revista/numeros/vol16-n3-162-165.pdf>.

[Consulta: 05/03/2013].

(ST) COPELli, Silvia B. (2012): «Síndrome de Turner: el riesgo de tumores gonadales en pacientes con secuencias del cromosoma Y», Revista Argentina de Endocrinología y Metabolismo, 49, 4, 195-202 [en línea]: $<$ http://www.scielo.org.ar/scielo.php?pid=S1851-

30342012000400005\&script=sci_arttext $>$. [Consulta: 03/03/2013].

(TAPFP) CANDIELlO, Alfonsina et al. (2012): «Tratamiento antiagregante guiado por pruebas de función plaquetaria en pacientes sometidos a angioplastia coronaria exitosa», Revista Argentina de Cardiología, 80, 354-359 [en línea]: $<$ http://www.scielo.org.ar/scielo.php?script=sci_arttext\&pid=S185037482012000500006>. [Consulta: 04/03/2013].

(TCPHD) JAIMOVICH, Gregorio et al. (2012): «Trasplante de Células Progenitoras Hematopoyéticas de Donante no relacionado en 61 Pacientes. Período 2004-2010», Hematología, 16, 2, 69-78 [en línea]: <http://www.sah.org.ar/revista/numeros/vol16-n269-78.pdf $>$. [Consulta: 03/03/2013]. 
(TLPM) TARTAS, Norma E. (2012): «Tratamiento del linfoma primario de mediastino (LPM). ¿Algo diferente del R-CHOP?», Hematología, 16, 3, 166-169 [en línea]: <http://www.sah.org.ar/revista/numeros/vol16-n3-166-169.pdf>. [Consulta: 04/03/2013].

(VLRTI) BARBARISI, Maximilano et al. (2012): «La vía laparoscópica para la restitución del tránsito intestinal luego de la operación de Hartmann. Consideraciones técnicas y resultados», Revista Argentina de Cirugía, 102, 28-36 [en línea]: $<$ http://www.scielo.org.ar/scielo.php?pid=S2250639X2012000100005\&script=sci_arttext $>$. [Consulta: 03/03/2013].

(VPTH) SAAVEDRA, M. S. et al. (2012): «Valores de PTH en pacientes bajo tratamiento con bifosfonatos», Revista Argentina de Endocrinología y Metabolismo, 49, 2 , 62-69 [en línea]: <http://www.scielo.org.ar/scielo.php?script=sci_arttext\&pid=S185130342012000200002>. [Consulta: 04/03/2013]. 